\title{
Characteristics of distractions in the intensive care unit: how serious are they and who are at risk?
}

\author{
Kay Choong See $\underline{\operatorname{Se}}^{1}$, MBBS, MRCP, Jason $\underline{\text { hhua }}^{1}$, MBBS, MRCP, Amartya Mukhopadhyay ${ }^{1}$, MD, FRCP, Tow Keang $\underline{\text { Lim }}^{1}$, MBBS, FRCP
}

\begin{abstract}
INTRODUCTION Distractions and interruptions of doctor's work, although common and potentially deleterious in the intensive care unit (ICU), are not well studied.

METHODS We used a simple observational method to describe the frequency, sources and severity of such distractions, and explore at-risk situations in the ICU. Independent paired observers separately shadowed eight residents and three fellows for 38 sessions (over $100 \mathrm{hrs)} \mathrm{in} \mathrm{a} \mathrm{20-bed} \mathrm{medical} \mathrm{ICU.}$

RESULTS In total, 444 distractions were noted. Interobserver agreement was excellent at $99.1 \%$. The mean number of distractions/doctor/hr was $4.36 \pm 2.27$. Median duration of each distraction was 2 mins (interquartile range 2-4 mins; range $1-20$ mins). The top three initiators of distractions were other doctors (35.1\%), nurses (30.4\%) and oneself (18.7\%). Of the 444 distractions, 107 (24.1\%) were prolonged (lasting $\geq 5$ mins), 210 (47.3\%) led to a complete pause of current activity and $85(19.1 \%)$ led to complete abandonment of the current activity. On multivariate analysis, physician seniority, time of session and day of week did not predict frequency of distraction. After adjusting for time of session, day of week and type of current activity, urgent distractions (to see another patient, perform immediate procedures or administer medications) and physician juniority were associated with major distractions (complete interruption or termination of current activity), while only urgent distractions were associated with prolonged distractions.

CONCLUSION Distractions are common in the ICU and junior doctors are particularly susceptible to major distractions.
\end{abstract}

Keywords: distraction, fellow, intensive care, interruption, resident

\section{INTRODUCTION}

In medical practice, distractions and interruptions frequently occur $^{(1)}$ and can cause medical errors that may affect patient safety, ${ }^{(2,3)}$ possibly due to the disruption of cognitive processes. Distractions can lead to interruptions by breaking current task activity. They may be particularly deleterious in high-stakes environments such as the intensive care unit (ICU), where physicians are confronted with up to 1,000 pieces of information per patient every day. ${ }^{(4)}$

The characteristics of distractions in the ICU setting are not well studied. Baseline data are crucial to direct and assess the effects of quality improvement interventions. Apart from the frequency of distractions, ${ }^{(1,5)}$ knowledge of the nature of distractions, their impact on the original activity and the risk factors for these distractions would also be relevant. However, in general, we found that certain studies had omitted distractions that did not lead to interruptions. ${ }^{(5)}$ The tools used to study distractions have ranged from simple forms to complex instruments using proprietary software. ${ }^{(5-7)}$ Simple forms are likely to be more useful for individual ICUs to audit their own interventions. Thus, in the present study, we used a simple observational method to describe the frequency, sources and severity of distractions, and delineate at-risk situations in our ICU.

\section{METHODS}

The study took place in the 20-bed medical ICU of a 1,000-bed tertiary-care hospital. The average workday was 0730-1730 hrs on weekdays (Monday to Friday) and 0730-1230 hrs on weekends (Saturday and Sunday). The ICU operated as a 'closed' model, and other specialties were consulted as needed. Medical records were partially computerised. All observations were performed over six weeks from 11 May to 26 June 2011. The study protocol was approved by the Institutional Review Board. We were guided by the STROBE (Strengthening the Reporting of Observational Studies in Epidemiology) statement. ${ }^{(8)}$

Two physician-led ICU teams operated on weekdays and one on weekends. Each team consisted of one attending (consultant), one fellow (registrar) and two residents (medical officers). Outof-office hours were covered by one fellow and one resident. Residents and fellows were rotated into the ICU at monthly intervals.

To investigate the major burden of distractions, we chose to observe only residents and fellows during office hours. As the more senior doctors (attending or consultant) were likely to be in the ICU for only brief periods of time (e.g. during ward rounds), it was held that observation of senior doctors would not have accurately reflected the problem of distractions experienced by most physicians working in the ICU. A convenience sample of doctors was observed, according to the approach adopted in previous studies. ${ }^{(6,7)}$

We used structured paper forms to collect observational data. 'Distractions' were defined as breaks in attention, evidenced by observed behaviour such as orienting away from a task or responding verbally. 'Interruptions' were breaks in task activity, 
as evidenced by observed cessation of a task. ${ }^{(9)}$ As distractions may or may not lead to interruptions, we used the former term to encompass all events. Communications and actions that were part of current activity (e.g. procedure-related instructions by supervising staff during central line insertions) were not considered distractions or interruptions.

Current activity at the time of distraction, type of distraction, initiator of distraction and severity of distraction were all coded as numbers to facilitate data entry. Participation in ward rounds were taken as primarily administrative-type tasks that took place within a consultant-led ward round. Self-distractions were distractions initiated by the doctor being observed and not by any external party. We defined urgent distractions as those that involved requests to see another patient, perform immediate procedures or administer medications. The duration of distractions was measured to the nearest minute, and distractions that lasted $\geq 5$ mins were deemed to be prolonged.

The severity of distractions was graded in a manner similar to prior research, ${ }^{(9)}$ as follows: (a) no effect on activity; (b) momentary pause (activity resumes during distraction); (c) complete pause (activity resumes only after distraction ceases); and (d) doctor abandons activity and attends to distraction. The latter two categories were considered to constitute major distractions. Although a recent publication had used a similar observational instrument, ${ }^{(1)}$ ours was developed independently. Each distraction was observed until it ended. Prolonged distractions were not considered to be major distractions if the current activity was unaffected or resumed during the distraction.

Our observers consisted of three fixed pairs of nursing students in their third (final) year of studies, with each having about a year of practical ward experience. Each observer underwent a onehour didactic lecture and a one-hour directly observed dummy session conducted by the first author. The three pairs of observers undertook the observations equitably and independently. Each pair of nursing students was at the hospital approximately twice a week and observed any of the ICU doctors who were working at that time. There was no selection bias for the doctors observed, as they did not work solely on specific days and the nursing students did not time their observation sessions according to any particular doctor's schedule. During the observation sessions, the observers kept an appropriate distance from the observed doctors and did not interrupt them or other ICU staff (shadowing technique). ${ }^{(7)}$ Observations were carried out without advance warning to the doctors and regardless of whether the doctors were involved in ward rounds. Verbal consent was taken immediately before observation of all doctors. The observers noted their findings separately.

We aimed to collect at least 100 hrs of observational data, which would be twice the duration of observations previously undertaken in the largest dedicated ICU study to date. ${ }^{(10)}$ Pearson's correlation analysis was performed for the distraction counts by the first and second observer in each pair. Other statistical analyses were not performed for interobserver correlations, as the observations showed near-perfect concordance (for all characteristics of the observations, including frequency, current activity and type, initiator and severity of distraction). This was possible since the frequency of distractions observed per hour was manageable for accurate data capture.

All other analyses were based on the observations collected by the first observer of each pair. Multiple linear regression was performed to analyse any effects of physician seniority (considered senior if the doctor has been in medical practice for $\geq 3 \mathrm{yrs}$ ), time of session (morning/afternoon) or day of week (weekday/weekend) on distraction frequency. Using major distraction (complete interruption or termination of current activity) and prolonged distraction ( $\geq 5$ mins) as outcomes, binary logistic regression analyses were performed using physician seniority, urgency of distraction, time of day, day of week and type of current activity as explanatory variables.

We broadly classified the types of current activities into administrative, procedural and communication activities. Continuous data was expressed as mean \pm standard deviation and non-parametric data was expressed as median (interquartile range $[I Q R])$. Statistical significance was assumed if $p$-value was $<0.05$. All analyses were performed using the Statistical Package for the Social Sciences version 19.0 (SPSS Inc, Chicago, IL, USA) and Stata version 11 (StataCorp LP, College Station, TX, USA) software.

\section{RESULTS}

A total of 11 doctors (age range 24-34 years) were observed, including 8 residents ( 6 men), and 3 fellows (all men). One male resident was a senior doctor in medical practice for more than three years who was on attachment to the ICU, while the others had work experience ranging from six months to two years. Four doctors (one senior resident and three fellows) were considered to be senior doctors. All doctors who were approached agreed to participate in the study.

A total of 38 observation sessions were carried out - 23 morning sessions (0700-1200 hrs) and 15 afternoon sessions (1201-1800 hrs). Of these, 26 sessions were on weekdays and 12 were on weekends. Residents were observed during 30 sessions, while fellows were observed during the remaining 8 sessions. Residents were observed proportionally more often than fellows, as ICU fellows at our institution had other concurrent non-ICU duties such as performing bronchoscopies at the endoscopy suite and running outpatient clinics. Therefore, fellows could not be observed during their periods of non-ICU duties.

The total number of distractions was 444. Interobserver agreement was excellent - 440 (99.1\%) observations were the same quantitatively and qualitatively. Pearson's correlation coefficient of the distraction counts between the two observers for each session was 0.998 . No observation fatigue was reported.

The median duration of each session was 180 mins (IQR 150-180 mins; range 60-210 mins). The total duration of observation was 6,025 mins (or $100.4 \mathrm{hrs}$ ). The mean number of distractions/doctor/hr was $4.36 \pm 2.27$, which did not differ by the time of day (morning $4.3 \pm 2.6$; afternoon $4.5 \pm 1.6$; $t$-test $\mathrm{p}=0.720)$. The median duration of each distraction was 2 mins (IQR 2-4 mins; range 1-20 mins). 
A total of 107 (24.1\%) distractions were prolonged, lasting $\geq 5$ mins. Senior doctors were more frequently distracted by urgent tasks when compared to junior doctors, but the difference was not statistically significant $(25.0 \%$ vs. $19.8 \% ; p=0.312)$. There were no sequential distractions, i.e. first distraction leading to a change in activity, followed by a second distraction that affected the new activity. The characteristics of the distractions noted are shown in Table I.

Multiple linear regression showed that seniority of doctor, time of session or day of week had no effect on distraction frequency (Table II). The type of current activity was also not related to the time of day ( $p=0.113$; Fisher's exact test). After adjusting for the time of session, day of week and type of current activity, urgent distractions and juniority were found to be associated with major distractions (Table III). However, only urgent distractions were associated with prolonged distractions (Table IV). Compared to communication activities (such as examining patients, talking to patients, relatives or colleagues), doctors who were performing administrative activities (conducting ward round, writing or reading notes, typing medication or treatment orders) were less liable to be distracted (Table III).

\section{DISCUSSION}

Distractions in our ICU were common ( 4.5 distractions/doctor/hr) and usually of short duration ( 2 mins each). The number of distractions was not influenced by physician seniority and time or day of week. Urgent distractions and juniority were associated with major distractions, and only urgent distractions were associated with prolonged distractions. Our results suggest that our observational instrument, while simple to use, was highly reliable in the ICU setting.

Prior studies were found to have yielded comparable frequencies of distractions, ${ }^{(1,5)}$ validating our simple observational method. For instance, Ballermann et al found a mean interruption rate of 3.8 times per hour among ICU physicians. (5) A more recent study reported a frequency of 6.5 times per hour, although this finding was based on data from only three ICU shifts. ${ }^{(1)}$ Nonetheless, these studies suggest that distractions in the ICU are less frequent than in emergency departments ( 7-10 per hour). ${ }^{(3,6)}$

We found that both physicians and nurses were equally liable to distract residents/fellows in the ICU, and this finding is similar to that in the emergency department. ${ }^{(6)}$ This is, however, unlike the situation in a general healthcare setting, where nurses and bleepers were reported to be the main sources of distractions. ${ }^{(1)}$ We also found that, in the ICU, self-distraction was as frequent as distraction by other doctors, unlike in the emergency department, where the converse was true. ${ }^{(6,7)}$ In our study, the low number of distractions from relatives was due to visitation restrictions (i.e. lunch time and evenings) at our centre. It is unclear why current administrative activities were negatively associated with major distractions. However, we believe that this finding was likely related to the shorter duration of administrative activities that our doctors engaged in, as compared to communication or procedural activities.
Table I. Characteristics of distractions $(n=444)$ experienced by residents/fellows in the intensive care unit.

\begin{tabular}{|c|c|}
\hline Variable & No. (\%) \\
\hline \multicolumn{2}{|l|}{ Current activity at the time of distraction } \\
\hline Writing notes & $97(21.8)$ \\
\hline Conducting ward round & $84(18.9)$ \\
\hline Entering treatment orders & $75(16.9)$ \\
\hline Reading notes & $61(13.7)$ \\
\hline Talking to a colleague & $47(10.6)$ \\
\hline Examining a patient & $37(8.3)$ \\
\hline Entering medication orders & $14(3.2)$ \\
\hline Performing non-sterile procedure & $11(2.5)$ \\
\hline Performing sterile procedure & $9(2.0)$ \\
\hline Talking to a patient & $3(0.7)$ \\
\hline Talking to a patient's relative & $3(0.7)$ \\
\hline Performing resuscitation & $2(0.5)$ \\
\hline Giving medications & $1(0.2)$ \\
\hline \multicolumn{2}{|l|}{ Type of distraction } \\
\hline Asked to speak to colleague & 177 (39.9) \\
\hline Asked to write treatment orders & $61(13.7)$ \\
\hline Asked to attend to a patient & $61(13.7)$ \\
\hline Asked to sign a document & $31(7.0)$ \\
\hline Going to the toilet & $30(6.8)$ \\
\hline Asked to perform a procedure & $29(6.5)$ \\
\hline Asked to speak to a patient's relative & $25(5.6)$ \\
\hline Drinking/eating & $21(4.7)$ \\
\hline Asked to write medication orders & $7(1.6)$ \\
\hline Asked to administer medications & $2(0.5)$ \\
\hline \multicolumn{2}{|l|}{ Initiator of distraction } \\
\hline Other doctor & $156(35.1)$ \\
\hline Nurse & $135(30.4)$ \\
\hline Self & $83(18.7)$ \\
\hline Phone call & $30(6.8)$ \\
\hline Other healthcare worker & $24(5.4)$ \\
\hline Relative & $14(3.2)$ \\
\hline Patient & $1(0.2)$ \\
\hline Monitor alarm & $1(0.2)$ \\
\hline \multicolumn{2}{|l|}{ Severity of distraction } \\
\hline No effect on activity & $13(2.9)$ \\
\hline Momentary pause* & $136(30.6)$ \\
\hline Complete pause $^{\dagger}$ & $210(47.3)$ \\
\hline Abandons activity and attends to distraction & $85(19.1)$ \\
\hline
\end{tabular}

*Activity resumes during distraction. †Activity resumes only after distraction ceases.

Table II. Multiple linear regression of factors affecting distraction frequency.

\begin{tabular}{|c|c|c|c|c|}
\hline Variable & $\begin{array}{l}\text { Reference } \\
\text { level }\end{array}$ & $\begin{array}{c}\text { Regression } \\
\text { coefficient } \\
(95 \% \mathrm{Cl})\end{array}$ & $\begin{array}{c}\text { Standardised } \\
\text { regression } \\
\text { coefficient }\end{array}$ & p-value \\
\hline $\begin{array}{l}\text { Seniority of } \\
\text { doctor (junior } \\
\text { vs. senior) }\end{array}$ & Senior & $\begin{array}{c}0.977 \\
(-0.953 \text { to } 2.907)\end{array}$ & 0.178 & 0.311 \\
\hline $\begin{array}{l}\text { Time of day } \\
\text { (morning vs. } \\
\text { afternoon) }\end{array}$ & Morning & $\begin{array}{c}0.029 \\
(-1.630 \text { to } 1.688)\end{array}$ & 0.006 & 0.972 \\
\hline $\begin{array}{l}\text { Day of week } \\
\text { (weekday vs. } \\
\text { weekend) }\end{array}$ & Weekday & $\begin{array}{c}0.960 \\
(-0.804 \text { to } 2.724)\end{array}$ & 0.199 & 0.276 \\
\hline
\end{tabular}

Cl: confidence interval

Our results highlighted the significance of distractions in the ICU setting. The great majority of distractions resulted in interruptions, and approximately $20 \%$ of distractions led to 
Table III. Logistic regression of risk factors for major distractions. *

\begin{tabular}{|c|c|c|c|}
\hline Variable & $\begin{array}{l}\text { Reference } \\
\text { level }\end{array}$ & $\begin{array}{l}\text { Odds ratio } \\
(95 \% \mathrm{Cl})\end{array}$ & p-value \\
\hline $\begin{array}{l}\text { Seniority of doctor } \\
\text { (junior vs. senior) }\end{array}$ & Senior & $2.91(1.22-6.96)$ & $0.016^{\| \prime}$ \\
\hline Urgency of distraction ${ }^{+}$ & Non-urgent & $1.90(1.09-3.33)$ & $0.024 \|$ \\
\hline $\begin{array}{l}\text { Time of day } \\
\text { (morning vs. afternoon) }\end{array}$ & Morning & $1.03(0.56-1.88)$ & 0.921 \\
\hline $\begin{array}{l}\text { Day of week } \\
\text { (weekday vs. weekend) }\end{array}$ & Weekday & $1.39(0.80-2.42)$ & 0.236 \\
\hline Administrative activity ${ }^{\ddagger}$ & $\begin{array}{l}\text { Communication } \\
\text { activity" }\end{array}$ & $0.30(0.17-0.51)$ & $<0.001^{\|}$ \\
\hline Procedural activity ${ }^{\S}$ & $\begin{array}{l}\text { Communication } \\
\text { activity" }\end{array}$ & $0.37(0.11-1.23)$ & 0.105 \\
\hline
\end{tabular}

* Major distraction: complete pause (activity resumes only after distraction ceases) or abandonment of activity, in order to attend to distraction. HUrgent distraction: asked to attend to a patient, perform a procedure or administer medications. ₹Administrative activity: conducting ward round, writing or reading notes, typing medication or treatment orders. §Procedural activity: giving medications, performing non-sterile procedure, sterile procedure or resuscitation. ICommunication activity: examining patient, talking to patient, relative or colleague. $\| \mathrm{p}<0.05$ was considered statistically significant. $\mathrm{Cl}$ : confidence interval

Table IV. Logistic regression of risk factors for prolonged distractions. *

\begin{tabular}{|c|c|c|c|}
\hline Variable & $\begin{array}{l}\text { Reference } \\
\text { level }\end{array}$ & $\begin{array}{l}\text { Odds ratio } \\
\text { (95\% Cl) }\end{array}$ & p-value \\
\hline $\begin{array}{l}\text { Seniority of doctor } \\
\text { (junior vs. senior) }\end{array}$ & Senior & $1.22(0.65-2.29)$ & 0.532 \\
\hline Urgency of distraction ${ }^{\dagger}$ & Non-urgent & $2.15(1.30-3.57)$ & $0.003^{\| \prime}$ \\
\hline $\begin{array}{l}\text { Time of day } \\
\text { (morning vs. afternoon) }\end{array}$ & Morning & $0.85(0.50-1.46)$ & 0.562 \\
\hline $\begin{array}{l}\text { Day of week } \\
\text { (weekday vs. weekend) }\end{array}$ & Weekday & $0.91(0.55-1.51)$ & 0.719 \\
\hline Administrative activity ${ }^{\ddagger}$ & $\begin{array}{l}\text { Communication } \\
\text { activity }\end{array}$ & $0.97(0.56-1.69)$ & 0.921 \\
\hline Procedural activity ${ }^{\S}$ & $\begin{array}{l}\text { Communication } \\
\text { activity }\end{array}$ & $1.11(0.38-3.26)$ & 0.852 \\
\hline
\end{tabular}

* Prolonged distraction: distraction lasting $\geq 5$ mins. +Urgent distraction: asked to attend to a patient, asked to perform a procedure or administer medications. ₹Administrative activity: conducting ward round, writing or reading notes, typing medication or treatment orders. §Procedural activity: giving medications, performing non-sterile procedure, sterile procedure or resuscitation. १Communication activity: examining patient, talking to patient, relative or colleague. $\| \mathrm{p}<0.05$ was considered statistically significant. $\mathrm{Cl}$ : confidence interval

complete abandonment of the prior activity. A comparable situation was reported in the emergency department, where doctors did not return to $18.5 \%$ of the interrupted tasks. ${ }^{(3)}$ Distractions may in turn lead to medical errors, ${ }^{(2,3)}$ which are common in the ICU. ${ }^{(11)}$ Possible interventions to avoid distractions include application of the 'sterile' cockpit concept in the form of a 'no interruption zone' and wearing 'do not disturb' vests. ${ }^{(12,13)}$ In addition, doctors and nurses could both develop situational awareness of distractions in order to minimise them.

One could argue that distractions can also be good for patient care, if doctors were required to urgently fulfill other tasks. We examined this reasoning and found that urgent tasks, such as examining patients for new and potentially important clinical signs, administering medications and performing procedures, were associated with both severe and prolonged distractions. These distractions were clinically necessary and justified. However, even after controlling for urgent tasks, junior doctors were still independently linked to major distractions. This could imply that junior doctors may be less capable of managing nonurgent distractions and that specialised training (e.g. didactic or simulation-based sessions) in this area may be helpful. Additionally, junior doctors were probably responsible for the tasks related to the distractions and this could have increased their vulnerability to distractions.

The strengths of our study include the consistent use of independent paired observers. This enabled us to internally validate our observational method. Our observers achieved an agreement rate of $99.1 \%$, which is similar to the overall agreement of $99.48 \%$ achieved using more complex methods. ${ }^{(6,7)}$ We also characterised distractions as fully as possible, including those that did not lead to interruptions. Our observation time, which exceeded $100 \mathrm{hrs}$ and was therefore higher than that reported by previous studies, ${ }^{(1,5,10)}$ helped to reduce sampling bias. We also chose to observe only residents and fellows (instead of including attendings), as they do most of the groundwork and bear the brunt of distractions in the ICU.

We acknowledge the limitations of our study. Our results are not generalisable to distractions after office hours. Although we studied only events in a medical ICU, the distraction frequency reported from a mixed medical-surgical ICU was similar. ${ }^{(5)}$ We observed only residents and fellows, as attending physicians are involved in important decision-making and distractions could have deleterious effects on them. In addition, the Hawthorne effect may have led participants to modify their activities based on the presence of an observer, but this effect may be minimal, especially with repeated exposure of the participants to research activities. ${ }^{(5,10)}$ While fluctuations in patient number, new admissions and seniority of the bedside nurse may have influenced the frequency and severity of distractions, we expected such variations to even out over the six weeks of observations. We did not determine whether tasks were completely and successfully handed over to another doctor so that interruptions were avoided, even though studies suggest that the process of handing over may also be fraught with difficulty. ${ }^{(14)}$ We also did not determine whether the distractions actually led to medical errors emanating from the original activity, although the latter has been shown to be true in the paediatric ICU and general ward settings. ${ }^{(2,15)}$ Even though distractions may not lead to clinical errors, they can harm work efficiency by prolonging the time required to complete the original task. ${ }^{(3,16)}$

We hope that our study will stimulate further research into the frequency and severity of medical errors caused by distractions. It is also important to differentiate the kinds of medical errors that stem from various types of current activities and distractions. While administrative activities may seem to be more benign tasks than procedural ones, distractions during the former may presumably disrupt systematic data gathering and the cognitive processes needed for accurate diagnoses. ${ }^{(17)}$ Indeed, a 
recent systematic review of autopsy studies suggested that major misdiagnoses occurred in $6 \%$ of ICU deaths and estimated that 40,500 adult patients in the United States may die with an ICU misdiagnosis annually. ${ }^{(18)}$

In conclusion, our study has found a high frequency of distractions in the ICU, and adds new information on the characterisation and risks for major distractions. Distractions frequently lead to interruptions while working, and junior doctors in our study were particularly susceptible to major distractions. Our simple observational instrument was both reliable and internally valid, and may facilitate future research in this area. Strategies for improving the quality and safety of ICU care should include interventions to manage distractions, especially among junior doctors.

\section{ACKNOWLEDGEMENTS}

The authors wish to thank the student nurses and lecturers from Ngee Ann Polytechnic, Singapore, for their enthusiastic participation in this study.

\section{REFERENCES}

1. Weigl M, Müller A, Zupanc A, Glaser J, Angerer P. Hospital doctors' workflow interruptions and activities: an observation study. BMJ Qual Saf $2011 ; 20: 491-7$.

2. Westbrook JI, Woods A, Rob MI, Dunsmuir WT, Day RO. Association of interruptions with an increased risk and severity of medication administration errors. Arch Intern Med 2010; 170:683-90.

3. Westbrook JI, Coiera E, Dunsmuir WT, et al. The impact of interruptions on clinical task completion. Qual Saf Health Care 2010; 19:284-9.

4. Morris $\mathrm{AH}$. Developing and implementing computerized protocols for standardization of clinical decisions. Ann Intern Med 2000; 132:373-83.

5. Ballermann MA, Shaw NT, Mayes DC, Gibney RT, Westbrook JI. Validation of the Work Observation Method By Activity Timing (WOMBAT) method of conducting time-motion observations in critical care settings: an observational study. BMC Med Inform Decis Mak 2011; 11:32.

6. Brixey JJ, Tang Z, Robinson DJ, et al. Interruptions in a level one trauma center: a case study. Int J Med Inform 2008; 77:235-41.

7. Brixey JJ, Robinson DJ, Turley JP, Zhang J. The roles of MDs and RNs as initiators and recipients of interruptions in workflow. Int J Med Inform 2010; 79:e109-15.

8. von Elm E, Altman DG, Egger M, et al. The Strengthening the Reporting of Observational Studies in Epidemiology (STROBE) statement: guidelines for reporting observational studies. Lancet 2007; 370:1453-7.

9. Healey AN, Sevdalis N, Vincent CA. Measuring intra-operative interference from distraction and interruption observed in the operating theatre. Ergonomics 2006; 49:589-604.

10. Tang Z, Weavind L, Mazabob J, et al. Workflow in intensive care unit remote monitoring: A time-and-motion study. Crit Care Med 2007; 35:2057-63

11. Valentin A, Capuzzo M, Guidet B, et al. Patient safety in intensive care: results from the multinational Sentinel Events Evaluation (SEE) study. Intensive Care Med 2006; 32:1591-8.

12. Anthony K, Wiencek C, Bauer C, Daly B, Anthony MK. No interruptions please: impact of a No Interruption Zone on medication safety in intensive care units. Crit Care Nurse 2010; 30:21-9.

13. Relihan E, O'Brien V, O'Hara S, Silke B. The impact of a set of interventions to reduce interruptions and distractions to nurses during medication administration. Qual Saf Health Care 2010; 19:e52.

14. Cook RI, Render M, Woods DD. Gaps in the continuity of care and progress on patient safety. BMJ 2000; 320:791-4.

15. Montgomery VL. Effect of fatigue, workload, and environment on patient safety in the pediatric intensive care unit. Pediatr Crit Care Med 2007; 8:S11-6.

16. Magrabi F, Li SY, Day RO, Coiera E. Errors and electronic prescribing: a controlled laboratory study to examine task complexity and interruption effects. J Am Med Inform Assoc 2010; 17:575-83.

17. Weinberg NS. The relation of medical problem solving and therapeutic errors to disease categories. QRB Qual Rev Bull 1989; 15:266-72.

18. Winters B, Custer J, Galvagno SM Jr, et al. Diagnostic errors in the intensive care unit: a systematic review of autopsy studies. BMJ Qual Saf 2012; 21:894-902. 